\title{
Identification of expressed $R$-genes associated with leaf spot diseases in cultivated peanut
}

\author{
Phat M. Dang ${ }^{1}\left(\mathbb{D} \cdot\right.$ Marshall C. Lamb ${ }^{1} \cdot$ Kira L. Bowen ${ }^{2} \cdot$ Charles Y. Chen $^{3}$
}

Received: 6 August 2018 / Accepted: 1 November 2018 / Published online: 30 November 2018

(c) The Author(s) 2018

\begin{abstract}
Peanut (Arachis hypogaea L.) is an important food and oilseed crop worldwide. Yield and quality can be significantly reduced by foliar fungal diseases, such as early and late leaf spot diseases. Acceptable levels of leaf spot resistance in cultivated peanut have been elusive due to environmental interactions and the proper combination of QTLs in any particular peanut genotype. Resistance gene analogs, as potential resistance $(R)$-genes, have unique roles in the recognition and activation of disease resistance responses. Novel $R$-genes can be identified by searches for conserved domains such as nucleotide binding site, leucine rich repeat, receptor like kinase, and receptor like protein from expressed genes or through genomic sequences. Expressed $R$-genes represent necessary plant signals in a disease response. The goals of this research are to identify expressed $R$-genes from cultivated peanuts that are naturally infected by early and late spot pathogens, compare these to the closest diploid progenitors, and evaluate specific gene expression in cultivated peanuts. Putative peanut $R$-genes (381) were available from a public database (NCBI). Primers were designed and PCR products were sequenced. A total of 214 sequences were produced which matched to proteins with the corresponding $R$-gene motifs. These $R$-genes were mapped to the genome sequences of Arachis duranensis and Arachis ipaensis, which are the closest diploid progenitors for tetraploid cultivated peanut, A. hypogaea. Identification and association of specific gene-expression will elucidate potential disease resistance mechanism in peanut and may facilitate the selection of breeding lines with high levels of leaf spot resistance.
\end{abstract}

Keywords Resistance gene analogs $\cdot \operatorname{RGAs} \cdot R$-genes $\cdot$ Markers $\cdot$ Cultivated peanut Disease resistance $\cdot$ Leaf spot . Genetic diversity

Electronic supplementary material The online version of this article (https://doi.org/10.1007/s11033-018-4464-5) contains supplementary material, which is available to authorized users.

Phat M. Dang

phat.dang@ars.usda.gov

Marshall C. Lamb

marshall.lamb@ars.usda.gov

Kira L. Bowen

bowenkl@auburn.edu

Charles Y. Chen

cyc0002@auburn.edu

1 USDA-ARS, National Peanut Research Laboratory, 1011 Forrester Dr. SE, PO Box 509, Dawson, GA 39842, USA

2 Department of Entomology and Plant Pathology, Auburn University, 209 Rouse, Auburn, AL 36849, USA

3 Department of Crop, Soil and Environmental Sciences, Auburn University, 258 Funchess Hall, Auburn, AL 36849, USA

\section{Introduction}

In response to different disease pressures, plants have evolved intricate recognition and signal transduction systems to ward off pathogens. On the leaf surface, plants have different layers of waxes, hairs or trichomes, and a cell wall that act as physical barriers against non-adapted pathogens. At the cell surface, the presence of the pathogen is first recognized by receptor like kinases (RLKs) and receptor like proteins (RLPs) which function as pattern recognition receptors (PRRs) in interactions called pathogen/microbeassociated molecular patterns (PAMP/MAMP) to activate a pattern-triggered immunity (PTI) response [1]. Non-adaptive pathogens are usually stopped from entering plant cells at this point. Adapted pathogens can penetrate the cells to release pathogenic effector proteins and activate resistance $(R)$ proteins of the host in a second line of defense, called effector triggered immunity (ETI) response [2]. In both PTI and ETI, plant activate an array of immune responses such 
as $\mathrm{Ca}^{2+}$ spike, reactive oxygen species (ROS) burst, MAP kinase (MAPK) activation, production of phytohormones, and modulation in transcriptional regulation [3].

Resistance $(R)$ or effector-receptor gene candidates have been associated with plant disease resistance and have been identified in important crop plants based on conserved DNA motifs through genome sequencing and homologous gene cloning [4-6]. There are seven conserved motifs or domains: Toll/interleukin-1 receptor (TIR), leucine zipper (LZ), coiled-coiled (CC), nucleotide-binding site (NBS), leucinerich repeat (LRR), transmembrane (TM), and serine-threonine kinase (STK) which can be broadly categorized into five main classes: TIR-NBS-LRR (TNL), CC-NBS-LRR (CNL), RLK, RLP, and other variations [2].

Peanut (Arachis hypogaea L.) is an important source of proteins, vitamins, and oil. It is grown in many parts of the world, with China and India as leading producers followed by Nigeria and USA [7]. Peanut is challenged by diseases, especially foliar diseases that have worldwide impact on yield and quality. Early leaf spot (ELS) caused by Cercospora arachidicola (Hori) and late leaf spot (LLS) caused by Phaeoisariopsis personata (Berk. \& M.A. Curtis) are important foliar fungal diseases that can cause complete defoliation and significantly reduce plant productivity. A combination of cultural practices such as crop rotation, proper management of residue by tillage practices [8], weather predictive models for disease outbreak $[9,10]$, and proper irrigation can minimize plant diseases. Application of fungicide can effectively control these diseases [11] but can be costly and maybe prohibited to subsistence peanut growing areas. Development of resistant peanut cultivars would be a sustainable solution for many parts of the world.

Because of the polyploidy nature of the cultivated peanut and the low DNA marker polymorphisms, progress in the application of marker-assisted plant breeding has been difficult. A large number $(>10,000)$ of simple sequence repeat (SSR) potential markers are available, but $<7 \%$ are polymorphic among cultivated peanuts [12]. Validated marker-trait associations for nematode resistance and high oleic chemistry have been applicable in breeding programs $[13,14]$. Recent research utilizing a recombinant inbred line (RIL) population that segregated for quantitative field resistance to LLS identified several quantitative trait loci (QTLs) [15]. Even with the discovery of a few candidate gene markers, application of marker-trait association continues to be a challenge since field performance evaluation, or phenotyping, can be significantly variable based on year, location, or environmental differences. Furthermore, defense responses and disease resistance $(R)$-gene activation have a fitness cost which can reduce plant growth and production [16]. In nature, plants select the 'perfect' combination of genes and coordinate gene-regulatory patterns necessary to ensure survival and productivity [17].
Recently, significant progress has been made in peanut genomics research which culminated in the sequencing of the two closest diploid peanut progenitors, Arachis duranensis and Arachis ipaensis [18], and the cultivated allotetraploid peanut (A. hypogaea) is now available through PeanutBase.org. Through a concerted genomics effort, there are currently 281,451 ESTs and a composite of 50,777 transcriptome shotgun assemblies (TSAs) archived on NCBI database. A first generation (58K) and a second generation (48K) single nucleotide polymorphism (SNP) chips have been utilized in different gene-expression experiments [19, 20]. These resources, as well as other bioinformatic projects in peanuts, provide a tremendous platform to identify functional genes that can lead to the development of disease resistant peanut varieties and was utilized to identify resistance gene analogs (RGAs), as resistance $(R)$-genes, associated with ELS and LLS. In peanuts, 78 RGAs were identified from peanut cultivar 'Tahu' and four diploid species [21] and later Yuksel et al. [22] identified 234 RGAs from cultivars 'Florunner' and 'UF-439-16-1003-2' from genomic DNA. Liu et al. [23] integrated previously identified RGAs with new EST sequences available at the time and derived 385 putative RGAs (156 contigs and 229 singletons).

The goals of this research are to identify and clone expressed $R$-gene candidates in peanut plants challenged with ELS and LLS pathogens and to associate these sequences with molecular pathways that may be used as disease resistant gene markers for peanut variety development. Gene-expression profiling of transcribed $R$-gene candidates in peanuts challenged with diseases provide a more comprehensive picture of disease resistance gene-regulation network and facilitate future peanut breeding.

\section{Materials and methods}

\section{Identification of $\boldsymbol{R}$-genes through database search}

RGA sequences were utilized from different groups [21-23]. All subsequent sequence nomenclatures are loosely assigned RGAs, or $R$-genes, to include all five major classes [2]. Sequence analyses were performed using Sequencher DNA analysis software (Gene Codes, Ann Arbor, MI, USA). Unique sequences with potential open reading frame (ORF) and with low E-value in BLASTx search (NCBI) results were selected for analysis. Sequences were searched against all Arachis EST and TSA NCBI databases (Online Resource 1). Sequences of each EST and TSA were downloaded and re-assembled to verify uniformity of each alignment and to obtain longer ORFs. Newly assembled sequences were evaluated to ensure the presence of an ORF and returned a significant BLASTx and HMMER (EMBL-EBI) matches to proteins with $R$-gene motifs [2]. Sequences that did not 
have ORFs and did not match to potential $R$-genes were not evaluated further.

\section{Peanut genotypes and plant treatment}

Two peanut varieties (Flavorrunner (FR) 458 and Georgia (Ga) 12Y), a breeding line (Exp27-1516), and a PI 268868 were evaluated. FR458, released in 1996, is a runner-type peanut that is highly susceptible to most peanut diseases and is utilized as a susceptible check to tomato spotted wilt (TSW), caused by Tomato spotted wilt virus [24]. Ga12Y, released in 2012, is also a runner-type peanut with resistance to TSWV and white mold or stem rot (caused by Sclerotium rolfsii Sacc.) [25]. Exp27-1516, a runner-type with medium resistance to ELS and LLS resistance and highly resistant to TSWV, was provided by Dr. Charles Chen (Auburn University) through a USDA/Auburn joint breeding program. PI 268868, a Virginia-type peanut with observed field resistance to ELS and LLS, was kindly provided by the USDA peanut germplasm repository in Griffin, GA. Seeds were planted at the rate of 6 seeds per $1 \mathrm{~m}$ row, with 6 row replicates randomly distributed in a $5.5 \times 12 \mathrm{~m}$ plastic house with screens on the sides for open air. Best agricultural plant treatment was utilized and no fungicides were applied throughout the growing season.

\section{Leaf spot disease evaluation and sample collection}

Visual assessment of leaf spot disease severity was based on a Florida 1-10 scale where 1 represents no disease or visual symptoms and 10 is complete leaf defoliation [26]. Leaf spot symptoms were assessed at three dates near the end of the growing season $(107,114$ and 121 days after planting, DAP) (Fig. 1). Leaf samples were collected at 121 DAP (3rd assessment), following the disease rating, for RNA analysis. This developmental stage represents late-season leaf spot infection, culminating to severe plant disease response and correlates to significant yield losses without fungicide applications. Fully expanded leaves were collected from a prominent stem from four randomly selected plants in $1 \mathrm{~m}$ linear row. Round punches $(2 \mathrm{~cm})$ of each leaf from four plants were pooled, placed into a $2 \mathrm{~mL}$ tube, frozen and stored at $-80{ }^{\circ} \mathrm{C}$ until processed.

\section{RNA extraction, CDNA synthesis and PCR product sequencing}

Total RNAs from fresh-frozen peanut leaves were extracted utilizing TRIzol Reagent (Ambion, Austin, TX, USA) according to manufacturer's instruction. RNA

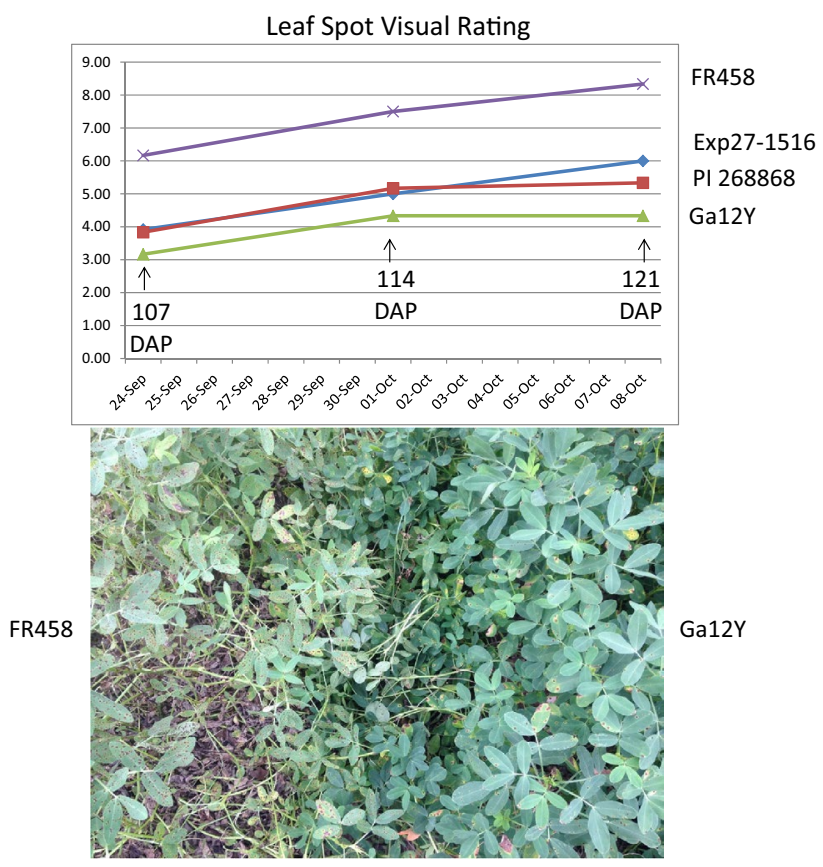

Fig. 1 Leaf spot progressive disease ratings, comparing four peanut genotypes near the end of the peanut growing season (top). These evaluations were based on a Florida scale from 1 to 10 with $1=$ no symptom and $10=$ complete defoliation. Picture of FR458 (susceptible) and Ga12Y (tolerant) to late-season leaf spot disease at 107 DAP (bottom)

was quantified using Nanodrop 2000 spectrophotometer (ThermoFisher Sci. Waltham, MA, USA) and quality was determined based on agarose gel electrophoresis analysis. RNA was DNase-treated with Turbo DNA-free (Ambion) prior to cDNA synthesis. $1 \mu \mathrm{g}$ total RNA was used as template and cDNAs were produced according to Dang et al. [27]. cDNAs were diluted 1:10 with sterile water and used as template in standard PCR reaction. Primers were designed using Clone Manager (Sci-Ed Software, Denver, $\mathrm{CO}$, USA) to obtain the largest ORF sequence possible for each predicted RGA (Online Resource 2). The $20 \mu \mathrm{L}$ PCR reaction consisted of $3 \mu \mathrm{L}$ of diluted cDNAs, $10 \mu \mathrm{L}$ GoTaq Green Master mix (Promega, Madison, WI, USA) and $0.4 \mu \mathrm{M}$ of each primer, with cycling conditions of 2 min at $94{ }^{\circ} \mathrm{C}$ to completely denature cDNAs, followed by 40 cycles of $20 \mathrm{~s}$ at $94{ }^{\circ} \mathrm{C}, 20 \mathrm{~s}$ at $55^{\circ} \mathrm{C}$ and $50 \mathrm{~s}$ at $72{ }^{\circ} \mathrm{C}$, and a final cycle $10 \mathrm{~min}$ at $72{ }^{\circ} \mathrm{C}$ to produce complete PCR products. PCR products were resolved on $1 \%$ TAE gelelectrophoresis, single bands at the predicted molecular weight were isolated and purified utilizing QIAquick Gel Extraction Kit (Qiagen, Valencia, CA, USA), and $80 \mathrm{ng}$ of purified-PCR products were sent for dideoxy-chain termination method sequencing (Eurofins MWG Operon, Louisville, KY, USA) with the forward or reverse specific primer. 


\section{Cloning of PCR products, plasmid isolation and sequencing}

Gel purified PCR products (50 ng) were cloned using StrataClone PCR Cloning Kit (Stratagene, San Diego, CA, USA). Single bacteria-colonies were selected and grown overnight at $37{ }^{\circ} \mathrm{C}$ with shaking with ampicillin antibiotic selection. Plasmids were extracted using QIAprep Spin Miniprep kit (Qiagen) and purified plasmids (300 ng) were sequenced (Eurofins) with T3 or T7 promoter sequencing primers.

\section{Quantitative (q) RT-PCR}

Diluted cDNAs were used as template in real-time fluorescence qRT-PCR with specific gene primers (Online Resource 3). Data was generated on QuantStudio7 Flex real-time PCR system (ThermoFisher Sci. Waltham, MA, USA) utilizing relative quantitation method as described by manufacturer. The $20 \mu \mathrm{L}$ reaction consisted of $3 \mu \mathrm{L}$ of diluted cDNAs, $10 \mu \mathrm{L}$ PowerUp SYBR green master mix (ThermoFisher Sci.) and $0.4 \mathrm{mM}$ of each primer, with PCR cycling conditions of $2 \mathrm{~min}$ at $50{ }^{\circ} \mathrm{C}, 10 \mathrm{~min}$ at $95{ }^{\circ} \mathrm{C}$, followed by 40 cycles of $15 \mathrm{~s}$ at $95{ }^{\circ} \mathrm{C}$ and $1 \mathrm{~min}$ at $58^{\circ} \mathrm{C}$, and a dissociation curve analysis cycle of $15 \mathrm{~s}$ at $95^{\circ} \mathrm{C}$, $20 \mathrm{~s}$ at $58{ }^{\circ} \mathrm{C}$ and $15 \mathrm{~s}$ at $95{ }^{\circ} \mathrm{C}$. The threshold cycle $(\mathrm{Ct})$ was automatically calculated by QuantStudio Real-Time PCR software (ThermoFisher Sci.) and relative expression was calculated based on $2^{-\Delta \Delta \mathrm{Ct}}$ described by Livak and Schmittgen [28]. All samples were first normalized to Actin (EZ723877) as an internal control then transformed data were normalized with FR458 $2^{-\Delta \Delta \mathrm{Ct}}$ values and compared with the other three peanut genotypes to determine relative fold changes in gene-expression.

\section{Results}

\section{Identification of potential $\boldsymbol{R}$-genes}

From over 400 initial $R$-gene candidate sequence targets, 381 were observed to have ORFs and matched BLASTx to proteins with $R$-gene motifs. These sequence sizes ranged from 404 to $3582 \mathrm{bp}$. Primers were designed to cover a large segment of predicted ORFs. Reverse-transcribed PCR analysis, utilizing RNA from leaf spot infected leaves, identified 241 primer-pairs that resulted in PCR products on agarose gelelectrophoresis. PCR products were purified and sequenced, resulting in a total of 214 RGA transcripts that produced ORFs and matched to an $R$-gene motif in BLASTx and HMMER searches (Table 1).

\section{Conservation of $\boldsymbol{R}$-genes in coding region}

SNPs were observed and reported for each $R$-gene (Table 2). From the 214 candidate RGAs, 172 produced observable PCR bands in four peanut genotypes and these products were cloned and sequenced. When sequencing results were compared, 86 RGAs had 0 SNP and 86 had between 1 and 16 SNPs in their respected DNA sizes (232-1776 bp). From the same set, 107 were identified to be single copy genes when electronically mapped to A. duranensis or A. ipaensis genomes, 64 had 2-5 allelic variants, and 2 had 7-10 variants.

\section{Discovery of insertions/deletions (indels)}

From the 214 RGAs identified, four indels were discovered through PCR product cloning. RGA 14a has a $1074 \mathrm{bp}$ length with a $6 \mathrm{bp}$ indel. Blastx search matched to a serine/threonine kinase HT1-like protein. RGA108, 348 bp in length containing a $9 \mathrm{bp}$ indel, codes for a TMV resistance $\mathrm{N}$-like protein. RGA188, 378 bp in length with a $3 \mathrm{bp}$ indel, codes for a receptor-like protein 12. RGA322a, 1369 bp in length with a $3 \mathrm{bp}$ indel, codes for a receptor-like protein kinase 5. These RGAs are all inframe indels that has potential add function to native transcripts.

\section{Mapping $R$-genes to peanut diploid genomes}

These sequences were searched using Blastn algorithm in NCBI database selecting Arachis as search organism. Verified sequencing transcripts were electronically mapped to A. duranensis or A. ipaensis genomes using Blastn algorithm utilizing NCBI nucleotide database (Table 3). Eighteen RGAs were mapped to A. duranensis (chromosome A01) and only 14 of the same RGAs mapped to A. ipaensis (B01), with 4 RGAs mapped to different $A$. ipaensis chromosomes. Thirteen RGAs mapped to A. duranensis (A02) and same RGAs were also mapped to A. ipaensis (B02), with an additional RGA108 mapped only to A. ipaensis. On chromosome 3, 34 RGAs were mapped to A. duranensis (A03) while only 32 mapped to A. ipaensis (B03). Twelve RGAs mapped to both A. duranensis (A04) and A. ipaensis (B04), with RGA 34 mapped only to A. duranensis (A04). RGAs 123, 265 and 293 mapped only to A. ipaensis (B04). On A. duranensis (A05) and A. ipaensis genomes (B05), 32 RGAs were mapped to both diploid chromosomes with an additional RGA 99 only present on A. duranensis genome (A05). Ten RGAs were mapped to both A. duranensis (A06) and $A$. ipaensis (B06) chromosomes, with an additional two RGAs 202 and 216 present on A. ipaensis genome (B06). Out of the 25 RGAs mapped to either A. duranensis (A07) or A. ipaensis (B07) chromosomes, only 11 were present on both diploid chromosomes. RGAs 91b, 170, 198, 202, 341 
Table 1 Identification of conserved $R$-gene motifs by HMMER and BLASTX searches and the associated protein functions

\begin{tabular}{|c|c|c|c|c|}
\hline ID & Domain & Class & Blastp description & qRT-PCR \\
\hline RGA002 & TNL & NBS & TMV resistance protein $\mathrm{N}$-like & \\
\hline RGA003 & LRR_RI & RLP & Plant intracellular Ras-group-related LRR protein 7 & $U p$ \\
\hline RGA004 & LRR_STKc & RLK & Receptor protein kinase TMK1 & \\
\hline RGA007 & STKc & Other & Serine/threonine-protein kinase At5g01020 & \\
\hline RGA009 & LRR_TM & RLP & DNA-damage-repair/toleration protein DRT100-like & \\
\hline RGA012 & LRR_STKc & RLK & Receptor-like protein kinase At1g35710 & \\
\hline RGA013 & CNL & NBS & Disease resistance protein RPP13 & \\
\hline RGA014a & STKc_MAP3K & Other & Mitogen-activated protein kinase kinase kinase & \\
\hline RGA016a & STKc & Other & Pto-interacting protein & \\
\hline RGA017 & LRR_STKc & RLK & Somatic embryogenesis receptor kinase & Down \\
\hline RGA020 & LRR_STKc & RLK & Receptor-like protein kinase At5g47070 & $U p$ \\
\hline RGA021 & LRR_STKc & RLK & Receptor-like serine/threonine-protein kinase At1g17230 & \\
\hline RGA023 & STKc & Other & Serine/threonine-protein kinase PBS1 & Down \\
\hline RGA025 & STKc & Other & Serine/threonine-protein kinase CDL1-like & \\
\hline RGA027 & LRR_STKc & RLK & Receptor kinase At5g58300 & \\
\hline RGA028 & STKc & Other & Serine/threonine-protein kinase $\mathrm{Cx} 32$, chloroplastic & $U p$ \\
\hline RGA031 & STKc & Other & Serine/threonine-protein kinase CDL1-like & \\
\hline RGA031a & STKc & Other & Serine/threonine-protein kinase CDL1-like & \\
\hline RGA033 & LRR_STKc & RLK & receptor-like protein kinase PEPR1 & \\
\hline RGA034 & LRR_STKc & RLK & Serine/threonine-protein kinase BAM3 & \\
\hline RGA035 & STKc & Other & Serine/threonine-protein kinase & $U p$ \\
\hline RGA036 & Mlo & Other & MLO-like protein & \\
\hline RGA037 & STKc & Other & Serine/threonine-protein kinase At1g01540 & \\
\hline RGA040b & STKc & Other & Cysteine-rich receptor-like protein kinase & Down \\
\hline RGA041 & LRR_STKc & RLK & Uncharacterized protein & \\
\hline RGA042 & LRR_STKc & RLK & Proline-rich receptor-like protein kinase PERK1 & Up \\
\hline RGA044 & TIR & NBS & Toll/interleukin-1 receptor-like protein & \\
\hline RGA047 & TNL & NBS & TMV resistance protein $\mathrm{N}$-like & \\
\hline RGA049 & LRR_TM & RLP & Polygalacturonase inhibitor-like & \\
\hline RGA051 & LRR_TM & RLP & DNA-damage-repair/toleration protein DRT100-like & Down \\
\hline RGA052 & LRR_STKc & RLK & Receptor-like serine/threonine-protein kinase At1g34110 & \\
\hline RGA054 & LRR_STKc & RLK & Receptor-like serine/threonine-protein kinase FEI 1 & $U p$ \\
\hline RGA055 & STKc & Other & Serine/threonine-protein kinase $\mathrm{Cx} 32$, chloroplastic & $U p$ \\
\hline RGA057 & LRR_STKc & RLK & Receptor-like protein kinase At5g47070 & $U p$ \\
\hline RGA058 & NL & NBS & TMV resistance protein $\mathrm{N}$-like & \\
\hline RGA059 & STKc & Other & Serine/threonine-protein kinase At5g01020 & \\
\hline RGA060 & TIR & NBS & TMV resistance protein $\mathrm{N}$ & Down \\
\hline RGA061 & TIR & NBS & TMV resistance protein $\mathrm{N}$ & \\
\hline RGA062 & LRR_STKc & RLK & Receptor-like kinase TMK4 & $U p$ \\
\hline RGA065 & LRR_STKc & RLK & Proline-rich receptor-like protein kinase PERK9 & Down \\
\hline RGA068 & TIR & NBS & TMV resistance protein $\mathrm{N}$-like & Up \\
\hline RGA069 & LRR_TM & RLP & Piriformospora indica-insensitive protein 2-like & \\
\hline RGA070 & STKc & Other & Rust resistance kinase Lr10-like & \\
\hline RGA073 & STKc & Other & Protein kinase 2B, chloroplastic-like & Mix \\
\hline RGA073a & STKc & Other & Protein kinase 2B, chloroplastic-like & \\
\hline RGA075 & LRR_STKc & RLK & Receptor-like protein kinase At4g00960 & \\
\hline RGA078 & STKc_MAPKK & Other & Mitogen-activated protein kinase kinase & Mix \\
\hline RGA079 & LRR_STKc & RLK & Receptor-like protein kinase HERK 1 & \\
\hline RGA082 & TIR & NBS & TMV resistance protein $\mathrm{N}$ & $U p$ \\
\hline RGA084 & LRR_STKc & RLK & Serine/threonine-protein kinase FLS2 & \\
\hline
\end{tabular}


Table 1 (continued)

\begin{tabular}{|c|c|c|c|c|}
\hline ID & Domain & Class & Blastp description & qRT-PCR \\
\hline RGA085 & TIR & NBS & TMV resistance protein $\mathrm{N}$-like & \\
\hline RGA086 & TIR & NBS & TMV resistance protein $\mathrm{N}$-like & Mix \\
\hline RGA087a & LRR_STKc & RLK & Receptor-like serine/threonine-protein kinase At4g34500 & \\
\hline RGA091b & STKc & Other & PTI1-like tyrosine-protein kinase At3g 15890 & Down \\
\hline RGA092 & STKc_MAP3K & Other & Mitogen-activated protein kinase kinase kinase & $U p$ \\
\hline RGA097 & LRR_STKc & RLK & Receptor-like protein kinase FERONIA & \\
\hline RGA098 & Hs1pro & Other & Nematode resistance protein-like HSPRO2 & Down \\
\hline RGA099 & STKc & Other & Protein kinase $2 \mathrm{~A}$, chloroplastic-like & Down \\
\hline RGA099a & STKc & Other & Protein kinase $2 \mathrm{~B}$, chloroplastic-like & \\
\hline RGA100 & LRR_TM & RLP & Receptor-like protein 12 & $U p$ \\
\hline RGA101a & STKc & Other & STRUBBELIG-RECEPTOR FAMILY 6 & $U p$ \\
\hline RGA102a & STKc & Other & Serine/threonine-protein kinase PBS1 & Down \\
\hline RGA103 & LRR_STKc & RLK & Serine/threonine-protein kinase BAM1 & \\
\hline RGA105 & LRR_RI & RLP & Polygalacturonase inhibitor 2-like & \\
\hline RGA106 & LRR_STKc & RLK & Serine/threonine-protein kinase At4g36180 & $U p$ \\
\hline RGA107 & LRR_STKc & RLK & Phytosulfokine receptor 2 & \\
\hline RGA108 & TIR & NBS & TMV resistance protein $\mathrm{N}$-like & Down \\
\hline RGA110 & LRR_STKc & RLK & Receptor-like protein kinase FERONIA & \\
\hline RGA113a & STKc & Other & Serine/threonine-protein kinase CDL1 & Down \\
\hline RGA116 & LRR_RI & RLP & Polygalacturonase inhibitor 2-like & Down \\
\hline RGA121a & LRR_STKc & RLK & Receptor-like kinase TMK4 & Up \\
\hline RGA123a & LRR_TM & RLP & Uncharacterized receptor-like protein & Down \\
\hline RGA124 & LRR_TM & RLP & DNA-damage-repair/toleration protein DRT100-like & \\
\hline RGA125 & TNL & NBS & TMV resistance protein $\mathrm{N}$-like & \\
\hline RGA126 & TNL & NBS & TMV resistance protein $\mathrm{N}$-like & \\
\hline RGA127 & TIR & NBS & Uncharacterized protein & Down \\
\hline RGA129 & LRR_STKc & RLK & Somatic embryogenesis receptor kinase 2-like & \\
\hline RGA130 & LRR_TM & RLP & Receptor-like protein 12 & \\
\hline RGA131 & C-CAP & Other & Adenylyl cyclase-associated protein & \\
\hline RGA132 & STKc & Other & Serine/threonine-protein kinase CDL1-like & \\
\hline RGA139 & TNL & NBS & Disease resistance protein At3g14460 & \\
\hline RGA140 & STKc & Other & PTI1-like tyrosine-protein kinase 3 & $U p$ \\
\hline RGA141 & STKc & Other & Uncharacterized protein & \\
\hline RGA144 & STKc & Other & STRUBBELIG-RECEPTOR FAMILY 7-like & Up \\
\hline RGA147b & STKc_MAP3K & Other & Mitogen-activated protein kinase kinase kinase & Down \\
\hline RGA148 & STKc & Other & Serine/threonine-protein kinase CDL1 & Down \\
\hline RGA151 & STKc & Other & Serine/threonine-protein kinase-like protein At3g51990 & \\
\hline RGA152 & STKc & Other & Calmodulin-binding receptor-like cytoplasmic kinase 2 & Mix \\
\hline RGA153b & STKc & Other & Serine/threonine-protein kinase SD1-8 & Down \\
\hline RGA154a & STKc & Other & Uncharacterized protein & Down \\
\hline RGA157 & LRR_TM & RLP & Disease resistance protein RGA1 & \\
\hline RGA161 & STKc & Other & Serine/threonine-protein kinase BIK1-like & Mix \\
\hline RGA162 & STKc & Other & Protein kinase $2 \mathrm{~B}$, chloroplastic-like & $U p$ \\
\hline RGA163 & STKc & Other & Chitin elicitor receptor kinase 1-like & \\
\hline RGA165 & STKc & Other & Uncharacterized protein & \\
\hline RGA166 & LRR_STKc & RLK & Serine/threonine-protein kinase RPK2 & Down \\
\hline RGA170 & LRR_STKc & RLK & Pollen receptor-like kinase 4 & \\
\hline RGA171 & LRR_STKc & RLK & BRASSINOSTEROID INSENSITIVE 1-associated receptor kinase & \\
\hline RGA172 & STKc_MAP3K & Other & Mitogen-activated protein kinase kinase kinase & Mix \\
\hline RGA177 & NL & NBS & Disease resistance protein At4g27220 & \\
\hline
\end{tabular}


Table 1 (continued)

\begin{tabular}{|c|c|c|c|c|}
\hline ID & Domain & Class & Blastp description & qRT-PCR \\
\hline RGA178 & Lectin_STKc & Other & L-type lectin-domain containing receptor kinase & \\
\hline RGA179 & STKc_MAP3K & Other & Serine/threonine-protein kinase CTR1-like & Mix \\
\hline RGA181 & Lectin-STKc & Other & G-type lectin S-receptor-like serine/threonine-protein kinase & Down \\
\hline RGA188 & LRR_STKc & RLK & Receptor-like protein kinase & \\
\hline RGA189 & STKc & Other & Wall-associated receptor kinase-like 20 & \\
\hline RGA191 & STKc & Other & Receptor-like protein kinase HERK 1 & \\
\hline RGA192 & Glyco_18 & Other & Cysteine-rich receptor-like protein kinase 10 & \\
\hline RGA197 & STKc & Other & Protein kinase 2B, chloroplastic-like & \\
\hline RGA198 & STKc & Other & Uncharacterized protein & Down \\
\hline RGA199 & STKc & Other & Receptor-like protein kinase At5g15080 & $U p$ \\
\hline RGA201 & LRR_STKc & RLK & Serine/threonine-protein kinase GSO2 & $U p$ \\
\hline RGA202 & STKc & Other & Serine/threonine-protein kinase NAK & Down \\
\hline RGA204 & Lectin-STKc & Other & L-type lectin-domain containing receptor kinase & \\
\hline RGA206 & LRR_TM & RLP & Disease resistance protein At5g66900 & $U p$ \\
\hline RGA207 & LRR_STKc & RLK & Serine/threonine-protein kinase RPK2 & Up \\
\hline RGA208 & TIR & NBS & TMV resistance protein $\mathrm{N}$-like & Down \\
\hline RGA210a & LRR_TM & RLP & Disease resistance protein RML1A-like & \\
\hline RGA211 & NL & NBS & Disease resistance protein RGA4 & \\
\hline RGA212 & STKc & Other & Uncharacterized protein & \\
\hline RGA213 & LRR_STKc & RLK & Serine/threonine-protein kinase At1g17230 & Mix \\
\hline RGA215 & STKc & Other & Wall-associated receptor kinase-like 14 & Down \\
\hline RGA216 & LRR_STKc & RLK & LRR receptor-like kinase & \\
\hline RGA218 & LRR_TM & RLP & Receptor-like protein 12 & \\
\hline RGA222 & STKc & Other & Pto-interacting protein 1-like & Down \\
\hline RGA223 & Lectin_STKc & Other & G-type lectin S-receptor-like serine/threonine-protein kinase & \\
\hline RGA226 & Lectin-STKc & Other & L-type lectin-domain containing receptor kinase & Down \\
\hline RGA229 & LRR_TM & RLP & Extensin-like protein 4 & \\
\hline RGA233 & STKc & Other & Protein LYK5 & \\
\hline RGA234 & LRR_STKc & RLK & Receptor-like protein kinase HAIKU2 & \\
\hline RGA235 & LRR_TM & RLP & BRASSINOSTEROID INSENSITIVE 1-like & $U p$ \\
\hline RGA236 & LRR_STKc & RLK & LRR receptor-like kinase & \\
\hline RGA237 & STKc_MAP3K & Other & Mitogen-activated protein kinase kinase kinase & Down \\
\hline RGA238 & STKc & Other & Uncharacterized protein & Down \\
\hline RGA240 & TIR & NBS & Disease resistance RPP13-like protein & Up \\
\hline RGA245a & LRR_STKc & RLK & Receptor-like protein kinase At5g24010 & Down \\
\hline RGA245b & LRR_STKc & RLK & Receptor-like protein kinase FERONIA & \\
\hline RGA246 & LRR_STKc & RLK & Receptor-like protein kinase At2g33170 & Down \\
\hline RGA249a & LRR_STKc & RLK & Receptor-like protein kinase At5g47070 & Down \\
\hline RGA249b & LRR_STKc & RLK & Receptor-like protein kinase At5g47070 & Down \\
\hline RGA250 & LRR_STKc & RLK & Receptor-like protein kinase At1g35710 & $U p$ \\
\hline RGA251 & LRR_STKc & RLK & Serine/threonine-protein kinase RPK2 & Down \\
\hline RGA252 & LRR_STKc & RLK & Wall-associated receptor kinase-like 20 & \\
\hline RGA253 & LRR_TM & RLP & TMV resistance protein $\mathrm{N}$-like & \\
\hline RGA253a & LRR_TM & RLP & disease resistance protein RPS6-like & Down \\
\hline RGA255 & LRR_STKc & RLK & Receptor-like protein kinase HAIKU2 & Mix \\
\hline RGA257 & LRR_STKc & RLK & Receptor-like protein kinase PXL2 & \\
\hline RGA259 & STKc & Other & Wall-associated receptor kinase-like 14 & \\
\hline RGA260 & STKc & Other & Uncharacterized protein & Up \\
\hline RGA261a & LRR_STKc & RLK & LRR receptor-like serine/threonine-protein kinase & \\
\hline RGA265 & TIR & NBS & TMV resistance protein $\mathrm{N}$-like & $U p$ \\
\hline
\end{tabular}


Table 1 (continued)

\begin{tabular}{|c|c|c|c|c|}
\hline ID & Domain & Class & Blastp description & qRT-PCR \\
\hline RGA266 & TIR & NBS & Uncharacterized protein & \\
\hline RGA268a & LRR_TM & RLP & Disease resistance protein At3g14460 & \\
\hline RGA269 & ATPase & Other & Plasma membrane ATPase 1-like & \\
\hline RGA270 & TNL & NBS & TMV resistance protein $\mathrm{N}$-like & $U p$ \\
\hline RGA275a & STKc & Other & Serine/threonine-protein kinase & \\
\hline RGA276 & TNL & NBS & TMV resistance protein $\mathrm{N}$-like & \\
\hline RGA278 & Lectin-STKc & Other & L-type lectin-domain containing receptor kinase & \\
\hline RGA278a & Lectin-STKc & Other & L-type lectin-domain containing receptor kinase & \\
\hline RGA286 & LRR_STKc & RLK & Receptor-like protein kinase At5g15080 & $U p$ \\
\hline RGA288 & Lectin-STKc & Other & L-type lectin-domain containing receptor kinase & Mix \\
\hline RGA289 & LRR_STKc & RLK & Serine/threonine/tyrosine-protein kinase SOBIR1 & \\
\hline RGA290 & LRR_TM & RLP & Disease resistance RPP13-like & \\
\hline RGA292 & LRR_TM & RLP & Receptor-like protein 12 & \\
\hline RGA293 & STKc & Other & Wall-associated receptor kinase-like & \\
\hline RGA296 & TIR & NBS & TMV resistance protein $\mathrm{N}$-like & \\
\hline RGA297b & STKc & Other & STRUBBELIG-RECEPTOR FAMILY 3-like & \\
\hline RGA298 & NL & NBS & TMV resistance protein $\mathrm{N}$-like & \\
\hline RGA300 & LRR_TM & RLP & Extensin-like protein 6 & \\
\hline RGA301 & LRR_STKc & RLK & Receptor protein kinase TMK1-like & \\
\hline RGA301a & LRR_STKc & RLK & Receptor protein kinase TMK1-like & \\
\hline RGA303 & STKc & Other & Phytosulfokine receptor 1 & \\
\hline RGA304 & LRR_STKc & RLK & Receptor-like serine/threonine-protein kinase BAM1 & $U p$ \\
\hline RGA307 & LRR_STKc & RLK & Uncharacterized protein & Down \\
\hline RGA310 & LRR_STKc & RLK & LEAF RUST DISEASE-RESISTANCE RECEPTOR PROT KINASE & \\
\hline RGA312 & LRR_STKc & RLK & Receptor-like serine/threonine-protein kinase At4g26540 & \\
\hline RGA313 & TNL & NBS & TMV resistance protein $\mathrm{N}$-like isoform & \\
\hline RGA314 & LRR_STKc & RLK & Receptor-like protein kinase HSL1 & $U p$ \\
\hline RGA315 & TIR & NBS & TMV resistance protein $\mathrm{N}$-like & $U p$ \\
\hline RGA318 & NL & NBS & TMV resistance protein $\mathrm{N}$-like & Down \\
\hline RGA319 & LRR_STKc & RLK & Receptor-like serine/threonine-protein kinase IRK & \\
\hline RGA321a & LRR_STKc & RLK & Receptor-like serine/threonine-protein kinase BAM1 & $U p$ \\
\hline RGA322 & LRR_STKc & RLK & Receptor-like protein kinase HSL1 & Mix \\
\hline RGA322a & LRR_STKc & RLK & Receptor-like protein kinase 5 & \\
\hline RGA327a & STKc & Other & PTI1-like tyrosine-protein kinase & \\
\hline RGA330 & LRR_STKc & RLK & BRASSINOSTEROID INSENSITIVE 1-like & \\
\hline RGA331 & LRR_STKc & RLK & LRR receptor-like serine/threonine-protein kinase & \\
\hline RGA336 & STKc & Other & Mitogen-activated protein kinase homolog MMK2-like & Down \\
\hline RGA337 & STKc & Other & Serine/threonine-protein kinase At1g01540 & \\
\hline RGA338 & STKc & Other & Protein kinase APK1B, chloroplastic-like & Down \\
\hline RGA340 & TIR & NBS & TMV resistance protein $\mathrm{N}$-like & $U p$ \\
\hline RGA341 & STKc & Other & Uncharacterized protein & $U p$ \\
\hline RGA342 & LRR_STKc & RLK & Receptor-like protein kinase At5g56460 & \\
\hline RGA343 & NL & NBS & Disease resistance protein RPM1-like & \\
\hline RGA344 & LRR_TM & RLP & Receptor-like protein 12 & \\
\hline RGA345 & LRR_TM & RLP & Receptor-like protein 12 & \\
\hline RGA347 & LRR_STKc & RLK & Receptor protein kinase MSP1-like & \\
\hline RGA348 & LRR_STKc & RLK & Receptor-like protein kinase At5g48380 & $U p$ \\
\hline RGA349 & LRR_STKc & RLK & Receptor protein kinase EMS1 & \\
\hline RGA352 & STKc & Other & Serine/threonine-protein kinase BRI1-like 2 & \\
\hline RGA354 & LRR_STKc & RLK & Somatic embryogenesis receptor kinase & \\
\hline
\end{tabular}


Table 1 (continued)

\begin{tabular}{llll}
\hline ID & Domain & Class & Blastp description \\
\hline RGA355 & STKc & Other & Calmodulin-binding receptor-like cytoplasmic kinase \\
RGA359 & STKc_Ubox & Other & U-box domain-containing protein \\
RGA360 & STKc & Other & Receptor-like protein kinase At5g18500 \\
RGA362 & STKc & Other & BRASSINOSTEROID INSENSITIVE 1-associated recept kinase \\
RGA364 & STKc & Other & Receptor-like protein kinase At2g42960 \\
RGA365 & STKc_Ubox & Other & U-box domain-containing protein \\
RGA366 & LRR_STKc & RLK & Receptor-like serine/threonine-protein kinase At1g74360 \\
RGA369 & LRR_STKc & RLK & Receptor-like serine/threonine-protein kinase At1g74360 \\
RGA370 & STKc & Other & Glycerophosphodiester phosphodiesterase protein kinase \\
RGA374 & LRR_STKc & RLK & Receptor protein kinase MSP1-like \\
RGA375 & Lectin-STKc & Other & G-type lectin S-receptor protein kinase \\
RGA377 & STKc_MAP3K & Other & Mitogen-activated protein kinase kinase kinase \\
RGA379 & LRR_STKc & RLK & Receptor-like serine/threonine-protein kinase BIR2 \\
RGA384 & LRR_STKc & RLK & Receptor-like serine/threonine-protein kinase At1g12460 \\
\hline
\end{tabular}

Real time qPCR results showed relative up- or down-regulations of $R$-genes. Positively correlated genes (labeled in italic) and negatively correlated genes (labeled in bold) are potential gene-expression markers for leaf spot resistance in peanut

and 374 were mapped only to $A$. duranensis (A07), while RGAs 27, 31, 36, 146, 148, 215, 314 and 369 mapped to $A$. ipaensis (B07) but were present on different $A$. duranensis chromosomes. Out of the 26 mapped to both $A$. duranensis (A08) and A. ipaensis (B08) chromosomes, 14 RGAs were represented in both. RGAs 3, 31, 36, 215, 314, 315, 366 and 369 were present on A. duranensis genome (A08) while same RGAs were on different A. ipaensis chromosomes. Fourteen RGAs were present on both A. duranensis (A09) and $A$. ipaensis (B09) chromosomes, while RGAs 91b and 170 were on A. ipaensis (B09) but on different A. duranensis chromosomes. RGA208 was only mapped to A. duranensis (A09) and not present on any A. ipaensis chromosomes. Out of the 25 RGAs represented on A. duranensis (A10) and $A$. ipaensis (B10) chromosomes, 16 RGAs were mapped on both diploid chromosomes. RGAs 27 and 148 were mapped to A. duranensis (A10) but on different A. ipaensis chromosomes. RGAs 3, 28, 54, 141, 366 and 374 were present on A. ipaensis (B10) but on different A. duranensis chromosomes. RGA165 was present on A. ipaensis genome (B10) but absent from any $A$. duranensis chromosomes.

\section{Relative gene-expression and correlation to leaf spot resistance}

Real time qPCR primers were designed and tested for efficiency (Online Resource 3). From the 89 RGAs that were evaluated for qRT-PCR, 39 were up-regulated and 38 were down-regulated (Fig. 2a, b). The remaining 12 were both up- and down-regulated (mix) among the 4 peanut genotypes tested. From the 39 up-regulated genes, 28 were identified as RLKs, 4 were RLPs, and 7 were TNLs. From the 38 down-regulated genes, 28 were RLKs, 5 were RLPs, and 5 were TNLs. From the remaining 12 genes, 10 were RLKs, 1 was an RLP, and 1 was a TNL. From the all 13 TNLs, 12 were associated with TMV resistance protein N-like and 1 code for a disease resistance RPPP13-like protein. When leaf spot susceptible peanut variety (FR458) was compared to the other 3 (more tolerant) peanut genotypes, $32 R$-genes were positively correlated (labeled in italic) and $32 R$-genes were negatively correlated (labeled in bold) with gene-expression levels (Table 1). These 64 candidate genes are potential gene-expression markers that can be utilized to select leaf spot resistance in peanut breeding programs.

\section{Discussions}

Plants are challenged with adverse biotic and abiotic pressures which require constant monitoring and modulating protective mechanisms, yet maintaining high productivity. For example, plants grown in high disease environments would invest more energy to maintain a "ready" state or be on a constant induction of disease responsive genes. RGAs, as $R$-genes, are essential in the plant immune system and are not well characterized in peanuts. From that aspect, a systematic approach was utilized to identify and sequence expressed $R$-genes in response to ELS and LLS pathogens.

Lately, there has been progress on the introgression and the identification of QTLs associated with ELS and LLS resistance [15, 29-32]. Because of a high number of QTLs and strong $\mathrm{G} \times \mathrm{E}$ interactions, predicting consistent disease resistance traits across different peanut genotypes is difficult. Identification of expressed $R$-genes in cultivated 
Table 2 RGAs associated with the numbers of SNPs and the predicted allelic variants observed in A. duranensis (D) and A. ipaensis (I) diploid genomes

\begin{tabular}{|c|c|c|c|c|c|c|c|c|c|}
\hline RGA ID & \# SNPs & Size & \# Var. & Diploids & RGA ID & \# SNPs & Size & \# Var. & Diploids \\
\hline RGA002 & 0 SNPs & 1653 & 3 Var. & $\mathrm{I}, \mathrm{D}$ & RGA003 & 4 SNPs & 712 & Single & I, D \\
\hline RGA013 & 0 SNPs & 977 & 3 Var. & I, D & RGA004 & 6 SNPs & 1736 & Single & I, D \\
\hline RGA016a & 0 SNPs & 975 & 3 Var. & $\mathrm{I}, \mathrm{D}$ & RGA012 & 4 SNPs & 810 & Single & I, D \\
\hline RGA020 & 0 SNPs & 917 & Single & $\mathrm{I}, \mathrm{D}$ & RGA017 & 4 SNPs & 597 & Single & $\mathrm{I}, \mathrm{D}$ \\
\hline RGA023 & 0 SNPs & 1334 & Single & $\mathrm{I}, \mathrm{D}$ & RGA021 & 6 SNPs & 1551 & Single & I, D \\
\hline RGA026 & 0 SNPs & 1551 & Single & I, D & RGA025 & 3 SNPs & 1191 & Single & I, D \\
\hline RGA027 & 0 SNPs & 1630 & 2 Var. & I, D & RGA028 & 4 SNPs & 677 & Single & I, D \\
\hline RGA031a & 0 SNPs & 1143 & Single & $\mathrm{I}, \mathrm{D}$ & RGA031 & 5 SNPs & 876 & Single & I, D \\
\hline RGA040b & 0 SNPs & 1300 & Single & $\mathrm{I}, \mathrm{D}$ & RGA033 & 9 SNPs & 1072 & Single & I, D \\
\hline RGA044 & 0 SNPs & 714 & Single & $\mathrm{I}, \mathrm{D}$ & RGA035 & 7 SNPs & 1000 & 2 Var. & I, D \\
\hline RGA047 & 0 SNPs & 1391 & 2 Var. & I, D & RGA037 & 5 SNPs & 1363 & Single & I, D \\
\hline RGA051 & 0 SNPs & 1242 & 2 Var. & I, D & RGA042 & 3 SNPs & 983 & Single & I, D \\
\hline RGA052 & 0 SNPs & 1711 & 3 Var. & I, D & RGA049 & 9 SNPs & 745 & Single & I, D \\
\hline RGA055 & 0 SNPs & 1122 & Single & $\mathrm{I}, \mathrm{D}$ & RGA054 & 10 SNPs & 1602 & 3 Var. & $\mathrm{I}, \mathrm{D}$ \\
\hline RGA057 & 0 SNPs & 919 & Single & $\mathrm{I}, \mathrm{D}$ & RGA062 & 6 SNPs & 1677 & Single & I, D \\
\hline RGA058 & 0 SNPs & 433 & 2 Var. & $\mathrm{I}, \mathrm{D}$ & RGA065 & 2 SNPs & 1084 & Single & $\mathrm{I}, \mathrm{D}$ \\
\hline RGA059 & 0 SNPs & 1059 & Single & I, D & RGA069 & 4 SNPs & 577 & Single & I, D \\
\hline RGA060 & 0 SNPs & 569 & Single & I, D & RGA073 & 11 SNPs & 1204 & 2 Var. & I, D \\
\hline RGA061 & 0 SNPs & 964 & 3 Var. & I, D & RGA075 & 5 SNPs & 1021 & 2 Var. & I, D \\
\hline RGA084 & 0 SNPs & 970 & Single & I, D & RGA103 & 9 SNPs & 1614 & Single & $\mathrm{I}, \mathrm{D}$ \\
\hline RGA086 & 0 SNPs & 453 & 3 Var. & $\mathrm{I}, \mathrm{D}$ & RGA106 & 5 SNPs & 1020 & Single & I, D \\
\hline RGA087a & 0 SNPs & 905 & 2 Var. & $\mathrm{I}, \mathrm{D}$ & RGA107 & 8 SNPs & 1386 & Single & I, D \\
\hline RGA091b & 0 SNPs & 851 & Single & $\mathrm{I}, \mathrm{D}$ & RGA110 & 11 SNPs & 859 & Single & I, D \\
\hline RGA099 & 0 SNPs & 1088 & 5 Var. & $\mathrm{I}, \mathrm{D}$ & RGA123 & 16 SNPs & 1302 & Single & I \\
\hline RGA100 & 0 SNPs & 1131 & 2 Var. & $\mathrm{I}, \mathrm{D}$ & RGA124 & 2 SNPs & 923 & Single & $\mathrm{I}, \mathrm{D}$ \\
\hline RGA101a & 0 SNPs & 1311 & Single & $\mathrm{I}, \mathrm{D}$ & RGA127 & 4 SNPs & 415 & Single & $\mathrm{I}, \mathrm{D}$ \\
\hline RGA102a & 0 SNPs & 1272 & Single & I, D & RGA130 & 11 SNPs & 1725 & 3 Var. & I, D \\
\hline RGA108 & 0 SNPs & 339 & Single & I & RGA132 & 7 SNPs & 598 & Single & $\mathrm{D}$ \\
\hline RGA113a & 0 SNPs & 885 & Single & I, D & RGA139 & 2 SNPs & 576 & 3 Var. & I, D \\
\hline RGA116 & 0 SNPs & 962 & Single & $\mathrm{I}, \mathrm{D}$ & RGA141 & 6 SNPs & 1668 & Single & $\mathrm{I}, \mathrm{D}$ \\
\hline RGA125 & 0 SNPs & 1031 & 3 Var. & $\mathrm{I}, \mathrm{D}$ & RGA146 & 5 SNPs & 822 & Single & $\mathrm{I}, \mathrm{D}$ \\
\hline RGA126 & 0 SNPs & 1332 & 3 Var. & I, D & RGA151 & 3 SNPs & 1143 & Single & I, D \\
\hline RGA129 & 0 SNPs & 461 & Single & I, D & RGA152 & 9 SNPs & 1120 & Single & I, D \\
\hline RGA140 & 0 SNPs & 964 & 2 Var. & $\mathrm{I}, \mathrm{D}$ & RGA161 & 13 SNPs & 1150 & Single & $\mathrm{I}, \mathrm{D}$ \\
\hline RGA144a & 0 SNPs & 1653 & Single & I, D & RGA162 & 3 SNPs & 972 & 2 Var. & I, D \\
\hline RGA157 & 0 SNPs & 1624 & 2 Var. & $\mathrm{I}, \mathrm{D}$ & RGA166 & 15 SNPs & 1654 & Single & $\mathrm{I}, \mathrm{D}$ \\
\hline RGA165a & 0 SNPs & 1189 & Single & I, D & RGA177 & 16 SNPs & 1658 & 4 Var. & I, D \\
\hline RGA170 & 0 SNPs & 1427 & Single & I, D & RGA179 & 2 SNPs & 1668 & Single & I, D \\
\hline RGA171 & 0 SNPs & 1554 & 2 Var. & I, D & RGA189 & 6 SNPs & 666 & Single & I, D \\
\hline RGA172 & 0 SNPs & 1148 & Single & $\mathrm{I}, \mathrm{D}$ & RGA191 & 2 SNPs & 1058 & Single & I, D \\
\hline RGA178 & 0 SNPs & 1752 & Single & $\mathrm{I}, \mathrm{D}$ & RGA198 & 8 SNPs & 641 & Single & $\mathrm{I}, \mathrm{D}$ \\
\hline RGA197 & 0 SNPs & 972 & 2 Var. & $\mathrm{I}, \mathrm{D}$ & RGA202 & 6 SNPs & 976 & Single & I, D \\
\hline RGA206 & 0 SNPs & 1165 & Single & I, D & RGA204 & 4 SNPs & 1380 & Single & I, D \\
\hline RGA207 & 0 SNPs & 1471 & Single & I, D & RGA213 & 6 SNPs & 816 & 2 Var. & I, D \\
\hline RGA210a & 0 SNPs & 498 & Single & I, D & RGA222 & 9 SNPs & 940 & 4 Var. & I, D \\
\hline RGA211 & 0 SNPs & 1125 & Single & $\mathrm{I}, \mathrm{D}$ & RGA223 & 5 SNPs & 1776 & Single & $\mathrm{I}, \mathrm{D}$ \\
\hline RGA212 & 0 SNPs & 1559 & Single & I, D & RGA226 & 4 SNPs & 793 & 2 Var. & I, D \\
\hline RGA218 & 0 SNPs & 615 & 2 Var. & I, D & RGA233 & 2 SNPs & 1625 & Single & I, D \\
\hline RGA218a & 0 SNPs & 347 & 3 Var. & I, D & RGA234 & 11 SNPs & 1747 & Single & I, D \\
\hline RGA224 & 0 SNPs & 714 & Single & I, D & RGA235 & 13 SNPs & 614 & 3 Var. & I, D \\
\hline RGA236 & 0 SNPs & 735 & Single & I, D & RGA246 & 2 SNPs & 1701 & Single & I, D \\
\hline
\end{tabular}


Table 2 (continued)

\begin{tabular}{|c|c|c|c|c|c|c|c|c|c|}
\hline RGA ID & \# SNPs & Size & \# Var. & Diploids & RGA ID & \# SNPs & Size & \# Var. & Diploids \\
\hline RGA237 & 0 SNPs & 1712 & 3 Var. & I, D & RGA251 & 15 SNPs & 1733 & Single & I, D \\
\hline RGA238 & 0 SNPs & 1142 & 2 Var. & I, D & RGA260 & 7 SNPs & 954 & 5 Var. & I, D \\
\hline RGA240 & 0 SNPs & 1153 & 3 Var. & $\mathrm{I}, \mathrm{D}$ & RGA265 & 5 SNPs & 736 & Single & I, D \\
\hline RGA252 & 0 SNPs & 1742 & Single & I, D & RGA286 & 8 SNPs & 1349 & Single & I, D \\
\hline RGA253 & 0 SNPs & 458 & 3 Var. & I, D & RGA312 & 12 SNPs & 1702 & Single & I, D \\
\hline RGA253a & 0 SNPs & 683 & 2 Var. & I, D & RGA338 & 9 SNPs & 1055 & 2 Var. & I, D \\
\hline RGA266 & 0 SNPs & 405 & 3 Var. & $\mathrm{I}, \mathrm{D}$ & RGA345 & 11 SNPs & 1652 & 3 Var. & $\mathrm{I}, \mathrm{D}$ \\
\hline RGA276 & 0 SNPs & 810 & 3 Var. & $\mathrm{I}, \mathrm{D}$ & RGA352 & 3 SNPs & 843 & Single & I, D \\
\hline RGA278a & 0 SNPs & 1505 & 2 Var. & I, D & RGA355 & 5 SNPs & 1337 & 2 Var. & I, D \\
\hline RGA289 & 0 SNPs & 1680 & Single & I, D & RGA356 & 11 SNPs & 1605 & Single & I, D \\
\hline RGA290 & 0 SNPs & 737 & 3 Var. & $\mathrm{I}, \mathrm{D}$ & RGA362 & 7 SNPs & 919 & Single & I, D \\
\hline RGA292 & 0 SNPs & 360 & 3 Var. & $\mathrm{I}, \mathrm{D}$ & RGA364 & 6 SNPs & 1458 & 4 Var. & $\mathrm{I}, \mathrm{D}$ \\
\hline RGA293 & 0 SNPs & 232 & Single & I & RGA366 & 11 SNPs & 1441 & 2 Var. & I, D \\
\hline RGA296 & 0 SNPs & 353 & Single & I, D & RGA375 & 2 SNPs & 363 & Single & I, D \\
\hline RGA297b & 0 SNPs & 1199 & 2 Var. & I, D & RGA378 & 13 SNPs & 1150 & Single & I, D \\
\hline RGA298 & 0 SNPs & 1661 & 2 Var. & $\mathrm{I}, \mathrm{D}$ & RGA379 & 9 SNPs & 1550 & Single & I, D \\
\hline RGA300 & 0 SNPs & 958 & Single & $\mathrm{I}, \mathrm{D}$ & RGA384 & 3 SNPs & 1287 & Single & $\mathrm{I}, \mathrm{D}$ \\
\hline RGA301a & 0 SNPs & 1422 & Single & $\mathrm{I}, \mathrm{D}$ & RGA073a & 4 SNPs & 1054 & 2 Var. & $\mathrm{I}, \mathrm{D}$ \\
\hline RGA319 & 0 SNPs & 1685 & 2 Var. & $\mathrm{I}, \mathrm{D}$ & RGA098 & 14 SNPs & 1066 & Single & $\mathrm{I}, \mathrm{D}$ \\
\hline RGA321a & 0 SNPs & 1573 & Single & I, D & RGA121a & 6 SNPs & 1524 & Single & I, D \\
\hline RGA330 & 0 SNPs & 1684 & Single & I, D & RGA147b & 4 SNPs & 1095 & Single & I, D \\
\hline RGA337 & 0 SNPs & 1521 & Single & $\mathrm{I}, \mathrm{D}$ & RGA153b & 3 SNPs & 602 & 4 Var. & $\mathrm{I}, \mathrm{D}$ \\
\hline RGA340 & 0 SNPs & 758 & 2 Var. & $\mathrm{I}, \mathrm{D}$ & RGA245b & 10 SNPs & 817 & 2 Var. & $\mathrm{I}, \mathrm{D}$ \\
\hline RGA341 & 0 SNPs & 774 & 2 Var. & I, D & RGA007 & $1 \mathrm{SNP}$ & 1199 & Single & I, D \\
\hline RGA342 & 0 SNPs & 872 & Single & I, D & RGA144 & $1 \mathrm{SNP}$ & 1695 & Single & I, D \\
\hline RGA343 & 0 SNPs & 560 & Single & I, D & RGA147 & 4 SNPs & 954 & Single & I, D \\
\hline RGA344 & 0 SNPs & 1033 & 2 Var. & I, D & RGA148 & $1 \mathrm{SNP}$ & 1290 & Single & $\mathrm{I}, \mathrm{D}$ \\
\hline RGA347 & 0 SNPs & 1590 & Single & $\mathrm{I}, \mathrm{D}$ & RGA165 & $1 \mathrm{SNP}$ & 542 & Single & $\mathrm{I}, \mathrm{D}$ \\
\hline RGA349 & 0 SNPs & 1661 & Single & $\mathrm{I}, \mathrm{D}$ & RGA259 & $1 \mathrm{SNP}$ & 1619 & 2 Var. & $\mathrm{I}, \mathrm{D}$ \\
\hline RGA359 & 0 SNPs & 1690 & 2 Var. & I, D & RGA268a & $1 \mathrm{SNP}$ & 899 & 10 Var. & I, D \\
\hline RGA360 & 0 SNPs & 1410 & Single & $\mathrm{I}, \mathrm{D}$ & RGA270 & $1 \mathrm{SNP}$ & 1091 & 7 Var. & I, D \\
\hline RGA363 & 0 SNPs & 1355 & Single & $\mathrm{I}, \mathrm{D}$ & RGA336 & $1 \mathrm{SNP}$ & 1021 & Single & $\mathrm{I}, \mathrm{D}$ \\
\hline RGA370 & 0 SNPs & 1650 & Single & I, D & RGA092a & 4 SNPs & 1164 & Single & I, D \\
\hline RGA374 & 0 SNPs & 636 & 2 Var. & I, D & RGA099a & $1 \mathrm{SNP}$ & 815 & 2 Var. & I, D \\
\hline RGA377 & 0 SNPs & 1524 & 3 Var. & I, D & RGA249b & 3 SNPs & 862 & Single & I, D \\
\hline
\end{tabular}

peanuts may help to further ascertain gene-expression patterns that may better correlate genetic backgrounds as well incorporating environmental (biotic and abiotic) responses that will result in leaf spot resistance. Because of the conserved sequence domains, homologous sequence cloning as well as bioinformatics approach have identified a high number of potential peanut RGAs [21-23]. The resulting number of potential $R$-genes is a representative of the search databases and included 205,442 ESTs from A. hypogaea (allotetraploid) and other diploids such as 35,291 from A. duranensis, 32,787 from A. ipaensis, 6264 from A. stenosperma, 750 from A. magna, 400 from $A$. appressipila, and 280 from A. Arabica, 75 from A. diogoi (NCBI EST database, August, 2018). $R$-gene conversion is correlated with sequence identity, close physical proximity on the chromosome, gene orientation, and recombination rate [33]. From the point of view that cultivated peanut ( $A$. hypogaea) came from two closest diploid progenitors ( $A$. duranensis and $A$. ipaensis), the number of $R$-genes from cultivated peanuts may be similar to the diploids. Indeed from the peanut diploid sequencing projects, 345 and 397 $R$-gene candidates were identified in A. duranensis and A. ipaensis genotypes, respectively [18], which closely approximate the number of identified candidate $R$-genes (381) in cultivated peanuts across different taxon. Mapping $R$-genes from cultivated peanuts onto diploid genomes (A and B) revealed that chromosomes 1-6 and 9 have similar set of genes. Chromosomes 7, 8, and 10 showed significant 
Table 3 Electronic mapping and placement of RGAs on A. duranensis and A. ipaensis chromosomes

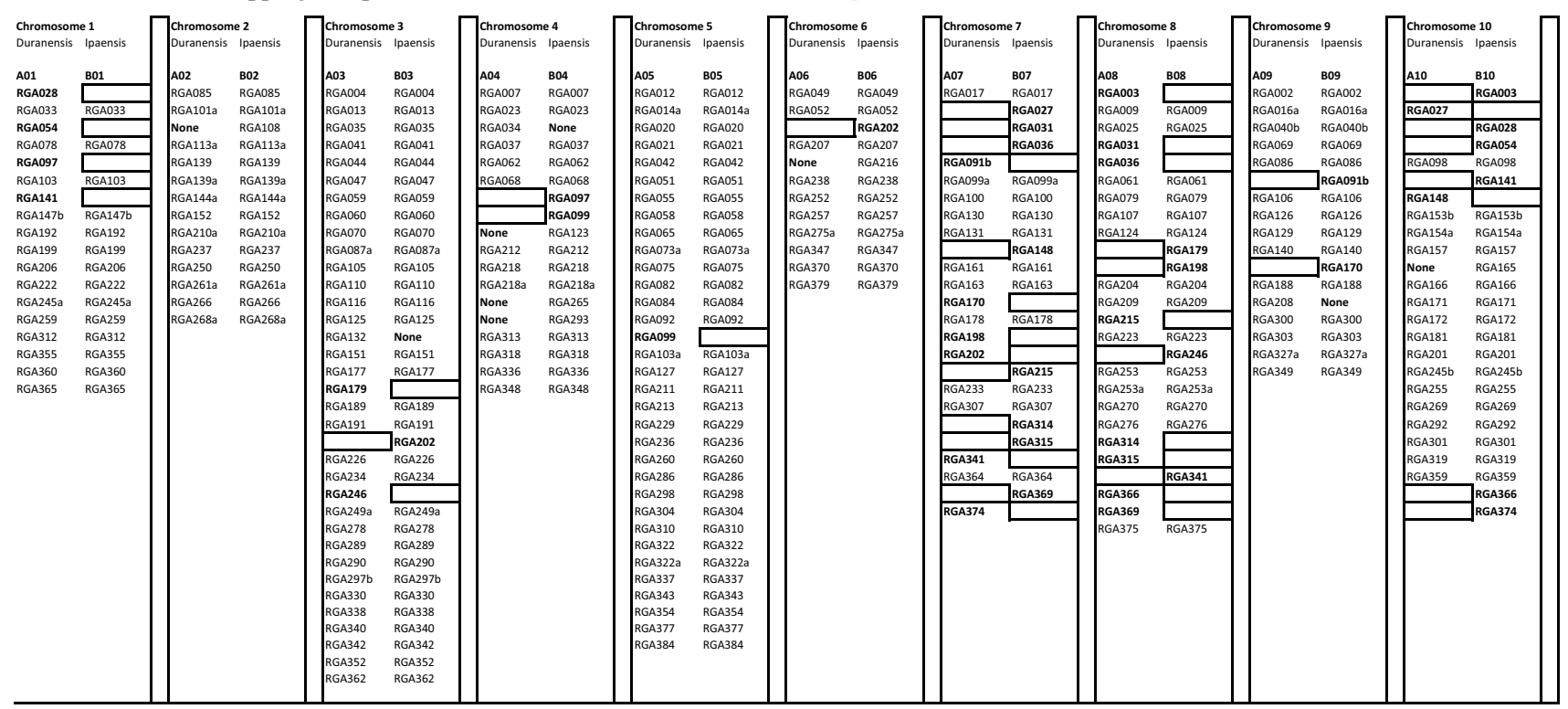

Empty boxes represent a different chromosome location. Bold characters represent more than 1 chromosome locations

divergent between $\mathrm{A}$ and $\mathrm{B}$ genomes in this study, verifying what was observed by Bertioli et al. [18] that chromosomes 7 and 8 have undergone complex rearrangements in DNA segment exchange. The importance of identification of disease resistance gene through evaluation of $R$-genes will complement molecular mapping of different peanut genomes.

Out of the 381 potential $R$-gene candidates, 214 were identified and sequenced. From these, 72 (34\%) were identified as RLKs and 25 (12\%) as RLPs. RLKs and RLPs are PRRs that can interact in PAMP/MAMP to initiate signal transduction to elevate plant immunity response. The two molecules are structurally similar with a signal peptide at the $\mathrm{N}$-terminus, extracellular domains to perceive the pathogen/ microbial pattern as LRRs, and transmembrane to anchor RLK and RLP in the plasma membrane [2]. In contrast to RLKs, RLPs lack an intracellular kinase domain and do not independently transduce perceived signal downstream. Notable examples of are Flg22 and EFR, bacterial PAMPs for flagellin and elongation factor Tu (EF-Tu) sensing, that recruit FLS2 and BAK1 to activate kinase signaling cascade to initiate plant immune response $[34,35]$. Receptor recognition of DNA, lipoproteins, peptidoglycans, and fungal chitin are also involved [36]. Plant resistance utilizing PRR activation has been thought to provide broad-spectrum resistance, but has not had much attention in breeding for disease resistance. In this study, 9 lectin-binding RLKs were identified (3 G-type and 6 L-type). In Arabidopsis, one of the largest class of RLKs are the L-type lectin receptor kinases (LecRKs) [37], and transgenic tobacco plants over-expressing Arabidopsis lectin receptor kinase gene (LecRK-1.9 or
LecRK-1X.1) show enhanced resistance to Phytophthora pathogens [38].

Another class designated as "other" variations included 85 (40\%) with STK domain. These included RGAs 016a and 222 that code for a pto-interacting protein 1-like; and RGAs 091b, 140, 327a which code for the corresponding ptil-like tyrosine-protein kinase important in disease resistance signaling mechanism in tomato [39]. In the mitogen-activated protein kinase (MAPK) signal transduction cascade, RGAs 014a, 092, 147b, 172, 237, and 377 code for mitogen-activated protein kinase kinase kinase; and RGA078 codes for a mitogen-activated protein kinase kinase. Plant MAPK cascades regulate a wide range of responses including stress, hormone regulation, innate immunity, and development [40]. RGA105 and 116 code for polygalacturonase-inhibiting protein gene 2. Expression of a polygalacturonase-inhibiting protein gene $2(M s P G I P 2)$ in alfalfa confer resistance to common leaf spot [41]. However in this study, RGA 116 was observed to be down-regulated compared to susceptible control, FR458. This may be a target for overexpression in plants to confer disease resistance.

Only 30 (14\%) are represented by $1 \mathrm{CNL}$ and $29 \mathrm{TNL}$ combined. A large number (22 RGAs) codes for TMV resistance protein $\mathrm{N}$-like and gene-expression may confer virus resistance [42]. Sequence variations for N-like proteins in peanut may recognize common Avr proteins in different viruses [43]. CNL and TNL are receptors that are regulated in ETI response, which can be stronger and longer than PTI response. In terms of $R$-gene evolution and transmission, it is theorized that $R$-genes are duplicated, rearranged, and/or mutated with synonomous 

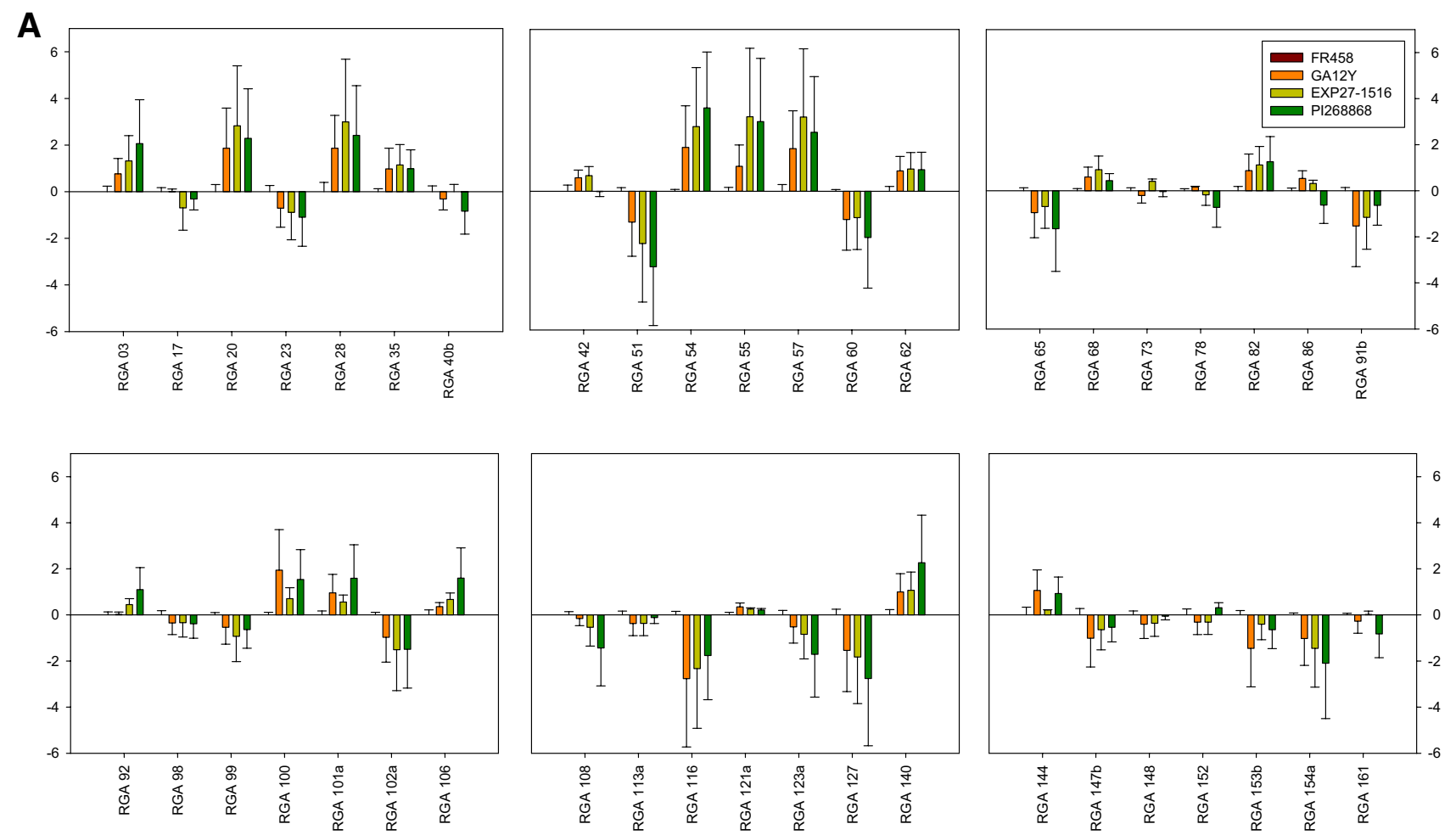

B
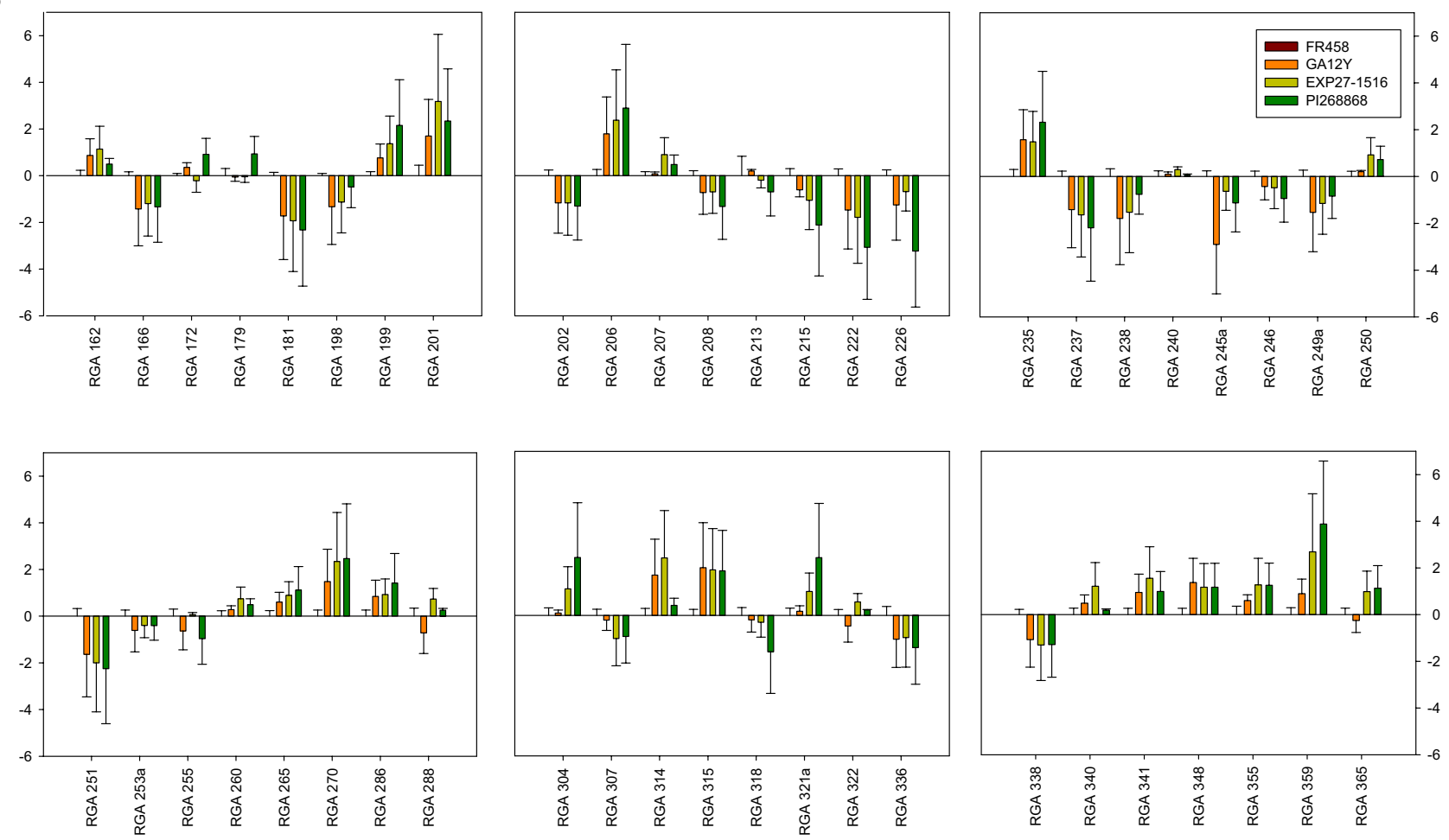

Fig. 2 a, b Relative gene-expression levels of RGAs. All samples were first normalized to Actin (EZ723877) as an internal control then transformed data were normalized with FR458 and compared to the other peanut genotypes to obtain relative gene-expression levels

or non-synonomous insertions/deletions (indels) or single nucleotide variations (SNPs) [44]. In this study, the majority of identified $R$-genes were observed to have low
DNA polymorphism. Out of the 172 RGAs cloned and sequenced, 86 (50\%) showed no SNPs and another 86 (50\%) showed fewer than 16 SNPs in expressed transcripts 
ranging from 232 to $1776 \mathrm{bp}$. Only four RGAs with different size indels (3-9 bp), representing synonomous and inframe indels, were discovered. In peanuts, expressed genes with indels can be associated with disease resistance [12] and peanut agronomic traits [45]. In rice, a major rice blast resistance gene Pi54 (Pikh), is associated with an NBS-LRR containing protein with a 144-bp insertion/ deletion (indel) [46]. The rest the $R$-genes showed high SNP polymorphism which may represent more than one allele for each transcript. Sequences with multiple variants, such as SNPs or indels, can code for different proteins and perhaps add new complementary function. For cultivated peanuts, these 214 RGAs represent transcript expression levels sufficient to be observed on agarose gelelectrophoresis analysis. Differences in the levels of geneexpression of RGAs can be associated to different levels of disease resistance, identifying potential disease resistance genes. Since the majority of the $R$-genes in study belong to PRRs and others with STK domains $(\sim 80 \%)$, it is difficult to draw a significant conclusion about all $R$-gene evolution in peanuts. In a study analyzing molecular phylogeny and evolution in legumes, $R$-genes were observed to undergo purifying selection instead of positive selection [47]. Initial low-frequency of genes introduced by random recombination may be lost (perhaps due lack of disease pressures, artificial selection by domestication, or fitness costs). The introgression wild peanut species may provide a novel source of disease resistance genes since some diploid peanuts have been observed to be more disease resistant than cultivated peanuts [48].

Disease resistance in plants is complex and involves a balance between disease responses and plant productivity. Comparison of disease susceptible versus more tolerant genotypes identified a group of up-regulated and downregulated $R$-genes that are potential targets for molecular breeding or applications in biotechnology. Research provides valuable information to understand disease resistance mechanism(s) relating to the gene-expression of $R$-genes in cultivated peanut and provides gene targets to develop disease resistant peanut varieties.

\begin{abstract}
Acknowledgements The authors are indebted to a group of dedicated individuals from the USDA-ARS National Peanut Research Laboratory, including Olivia Rogers, Courtney Shirley, Larry Powell, Kathy Gray, Sam Hilton, Staci Ingram, Robin Barfield, and Lori Riles. This work was supported by USDA-ARS project numbers 6604-21000-004-00D. Mention of trade names or commercial products in this article is solely for providing specific information and does not imply recommendation or endorsement by the US Department of Agriculture.
\end{abstract}

\section{Compliance with ethical standards}

Conflict of interest The authors have no conflict of interest to declare.
Open Access This article is distributed under the terms of the Creative Commons Attribution 4.0 International License (http://creativeco mmons.org/licenses/by/4.0/), which permits unrestricted use, distribution, and reproduction in any medium, provided you give appropriate credit to the original author(s) and the source, provide a link to the Creative Commons license, and indicate if changes were made.

\section{References}

1. Couto D, Zipfel C (2016) Regulation of pattern recognition receptor signaling in plants. Nat Rev Immunol 16:537-552

2. Sekhwal MK, Li PC, Lam I, Wang X, Cloutier S, You FM (2015) Disease resistance gene analogs (RGAs) in plants. Int J Mol Sci 16:19248-19290

3. Tsuda K, Somssich IE (2015) Transcriptional networks in plant immunity. New Phytol 206:932-947

4. Monosi B, Wisser RJ, Pennill L, Hulbert SH (2004) Fullgenome analysis of resistance gene homologues in rice. Theor Appl Genet 109:1434-1447

5. Kang YJ, Kim KH, Shim S, Yoon MY, Sun S, Kim MY et al (2012) Genome-wide mapping of NBS-LRR genes and their association with disease resistance in soybean. BMC Plant Biol 12:139

6. Jupe F, Pritchard L, Etherington GJ, Mackenzie K, Cock PJA, Wright $F$ et al (2012) Identification and localisation of the NBLRR gene family within the potato genome. BMC Genom 13:75

7. FAOSTAT (2016) Food and agriculture organization of the United Nations statistics division. http://faostat3fao.org/browse/Q/QD/E

8. Cantonwine EG, Culbreath AK, Stevenson KL (2007) Characterization of early leaf spot suppression by strip tillage in peanut. Phytopathology 97:187-194

9. Bailey JE, Johnson GL, Toth SJ (1994) Evolution of weatherbased peanut leaf spot spray advisory in North Carolina. Plant Dis 78:530-535

10. Olatinwo RO, Prabha TV, Paz JO, Hoogenboom G (2012) Predicting favorable conditions for early leaf spot of peanut using output from the weather research and forecasting (WRF) model. Int J Biometeorol 56:259-268

11. Woodward JE, Brenneman TB, Kemerait RC Jr, Culbreath AK, Smith NB (2010) Management of peanut diseases with reduced input fungicide programs in fields with varying levels of disease risk. Crop Prot 29:222-229

12. Liu L, Dang PM, Chen CY (2015) Development and utilization of indel markers to identify peanut (Arachis hypogaea) disease resistance. Front Plant Sci 6:988

13. Chu Y, Wu CL, Holbrook CC, Tillman BL, Person G, Ozias-Akins $P$ (2011) Marker-assisted selection to pyramid nematode resistance and the high oleic trait in peanut. Plant Genome 4:110-117

14. Janila P, Pandey MK, Shasidhar Y, Variath MT, Sriswathi M, Varshney RK et al (2016) Molecular breeding for introgression of fatty acid desaturase mutant alleles ( $a h F A D 2 A$ and $a h F A D 2 B$ ) enhances oil quality in high and low oil containing peanut genotypes. Plant Sci 242:203-213

15. Clevenger J, Chu Y, Chavarro C, Botton S, Culbreath A, Isleib TG et al (2018) Mapping late leaf spot resistance in peanut (Arachis hypogaea) using QTL-seq reveals markers for markerassisted selection. Front Plant Sci 9:83

16. MacQueen A, Bergelson J (2016) Modulation of $R$-gene expression across environments. J Exp Bot 67:2093-2105

17. Takatsuji H (2014) Development of disease-resistant rice using regulatory components of induced disease resistance. Front Plant Sci 5:630

18. Bertioli DJ, Cannon SB, Froennicke L, Huang GD, Farmer AD, Cannon EKS et al (2016) The genome sequences of Arachis 
duranensis and Arachis ipaensis, the diploid ancestors of cultivated peanut. Nat Genet 48:438-446

19. Pandey MK, Agarwall G, Kale SM, Clevenger J, Nayak SN, Varshney RK et al (2017) Development and evaluation of a high density genotyping 'Axiom_Arachis' array with 58 K SNPs for accelerating genetics and breeding in groundnut. Sci Rep 7:40577

20. Clevenger J, Chu Y, Chavarro C, Agarwal G, Bertioli DJ, Leal-Bertioli SCM et al (2017) Genome-wide SNP genotyping resolves signatures of selection and tetrasomic recombination in peanut. Mol Plant 10:309-322

21. Bertioli DJ, Leal-Bertioli SC, Lion MB, Santos VL, Pappas G, Cannon SB et al (2003) A large scale analysis of resistance gene homologues in Arachis. Mol Genet Genom 270:34-45

22. Yuksel B, Estill JC, Schulze SR, Paterson AH (2005) Organization and evolution of resistance gene analogs in peanut. Mol Genet Genom 274:248-263

23. Liu Z, Feng S, Pandey MK, Chen X, Culbreath AK, Varshney RK et al (2013) Identification of expressed resistance gene analogs from peanut (Arachis hypogaea $\mathrm{L}$ ) expressed sequence tags. $\mathrm{J}$ Integr Plant Biol 55:453-461

24. Branch WD, Brenneman TB, Culbreath AK (2003) Tomato spotted wilt virus resistance among high and normal $\mathrm{O} / \mathrm{L}$ ratio peanut cultivars with and without irrigation. Crop Prot 22(1):141-145

25. Branch WD (2013) Registration of 'Georgia-12Y' peanut. J Plant Regist 7(2):151-153

26. Chiteka ZA, Gorbet DW, Knauft DA, Shokes FM, Kucharek TA (1988) Components of resistance to late leafspot in peanut II correlations among components and their significance in breeding for resistance. Peanut Sci 15:76-81

27. Dang PM, Chen CY, Holbrook CC (2013) Evaluation of five peanut (Arachis hypogaea) genotypes to identify drought responsive mechanisms utilizing candidate-gene approach. Funct Plant Biol 40:1323-1333

28. Livak KJ, Schmittgen TD (2001) Analysis of relative gene expression data using real-time quantitative PCR and the $2^{-\triangle \Delta C T}$ method. Methods 25:402-408

29. Khera P, Pandey MK, Wang H, Feng S, Qiao L, Culbreath AK et al (2016) Mapping quantitative trait loci of resistance to tomato spotted wilt virus and leaf spots in a recombinant inbred line population of peanut (Arachis hypogaea $\mathrm{L}$ ) from SunOleic 97R and NC94022. PLoS ONE 11(7):e0158452

30. Kolekar RM, Sujay V, Shirasawa K, Sukruth M, Khedikar YP, Gowda MVC et al (2016) QTL mapping for late leaf spot and rust resistance using an improved genetic map and extensive phenotypic data on a recombinant inbred line population in peanut (Arachis hypogaea L). Euphytica 209:147-156

31. Pasupuleti J, Pandey MK, Manohar SS, Variath MT, Nallathambi P, Nadaf HL et al (2016) Foliar fungal disease-resistant introgression lines of groundnut (Arachis hypogaea $\mathrm{L}$ ) record higher pod and haulm yield in multilocation testing. Plant Breed 135:355-366

32. Zhou X, Xia Y, Liao J, Liu K, Li Q, Dong Y et al (2016) Quantitative trait locus analysis of late leaf spot resistance and planttype-related traits in cultivated peanut (Arachis hypogaea $\mathrm{L}$ ) under multi-environments. PLoS ONE 11:11

33. Guo YL, Fitz J, Schneeberger K, Ossowski S, Cao J, Weigel D (2011) Genome-wide comparison of nucleotide-binding site-leucine-rich repeat-encoding genes in Arabidopsis. Plant Physiol 157:757-769

34. Chinchilla D, Zipfel C, Robatzek S, Kemmerling B, Nurnberger T, Jones JD et al (2007) A flagellin-induced complex of the receptor FLS2 and BAK1 initiates plant defence. Nature 448:497-500

35. Zipfel C, Kunze G, Chinchilla D, Caniard A, Jones JDG, Boller T, Felix G (2006) Perception of the bacterial PAMP EF-Tu by the receptor EFR restricts Agrobacterium-mediated transformation. Cell 125:749-760

36. Macho AP, Zipfel C (2014) Plant PRRs and the activation of innate immune signaling. Mol Cell 54:263-272

37. Wang Y, Weide R, Govers F, Bouwmeester K (2015) L-type lectin receptor kinases in Nicotiana benthamiana and tomato and their role in Phytophthora resistance. J Exp Bot 66:6731-6743

38. Wang Y, Cordewener JHG, America AHP, Shan W, Bouwmeester K, Govers F (2015) Arabidopsis lectin receptor kinases LecRKIX1 and LecRK-IX2 are functional analogs in regulating Phytophthora resistance and plant cell death. Mol Plant Microbe Interact 28:1032-1048

39. Sessa G, D'Ascenzo M, Loh YT, Martin GB (1998) Biochemical properties of two protein kinases involved in disease resistance signaling in tomato. J Biol Chem 273:15860-15865

40. Rodriguez MC, Petersen M, Mundy J (2010) Mitogen-activated protein kinase signaling in plants. Annu Rev Plant Biol 61:621-649

41. Gui Z, Gao JM, Xin N, Wang Y, Pi YS, Liu HQ et al (2016) Association of polygalacturonase-inhibiting protein gene 2 ( $M s P$ GIP2) to common leaf spot resistance in alfalfa. Eur J Plant Pathol 144:245-256

42. Balaji B, Cawly J, Angel C, Zhang ZY, Palanichelvam K, Cole A et al (2007) Silencing of the $N$ family of resistance genes in Nicotiana edwardsonii compromises the hypersensitive response to Tombus viruses. Mol Plant Microbe Interact 20:1262-1270

43. Sekine KT, Tomita R, Takeuchi S, Atsumi G, Saitoh H, Mizumoto $\mathrm{H}$ et al (2012) Functional differentiation in the leucine-rich repeat domains of closely related plant virus-resistance proteins that recognize common Avr proteins. Mol Plant Microbe Interact 25:1219-1229

44. Ajawatanawong P, Baldauf SL (2013) Evolution of protein indels in plants, animals and fungi. BMC Evol Biol 13:140

45. Meng S, Yang XL, Dang PM, Cui SL, Mu GJ, Chen CY et al (2016) Evaluation of insertion-deletion markers suitable for genetic diversity studies and marker-trait correlation analyses in cultivated peanut (Arachis hypogaea L). Genet Mol Res 15(3): gmr8207

46. Ramkumar G, Srinivasarao K, Mohan KM, Sudarshan I, Sivaranjani AKP, Gopalakrishna K et al (2011) Development and validation of functional marker targeting an indel in the major rice blast disease resistance gene Pi54 (Pik(h)). Mol Breed 27:129-135

47. Zheng FY, Wu HY, Zhang R, Li S, He W, Wong FL et al (2016) Molecular phylogeny and dynamic evolution of disease resistance genes in the legume family. BMC Genom 17:402

48. Favero AP, Moraes SA, Garcia AAM, Valls JFM, Vello NA (2009) Characterization of rust, early and late leaf spot resistance in wild and cultivated peanut germplasm. Sci Agric 66:110-117 